\title{
Renal Denervation Therapy (RDT) in Resistant Hypertension
}

\author{
AMIN MG ${ }^{\mathrm{a}}$, HAQUE HF
}

\begin{abstract}
:
Resistant hypertension is defined as blood pressure that remains above therapeutic goal despite the use of three antihypertensive drugs including a diuretic. As much as one third of patients with arterial hypertension are treatmentrefractory as they do not reach sufficient blood pressure control despite combination antihypertensive therapy of significant duration. The hyperactivity of sympathetic nervous system (SNS) in the occurrence of treatment-resistant long standing hypertension has been established both in animal models and in clinical practice. In these patients, the kidneys play a central role as an activator of the sympathetic nervous system. The failure of purely pharmacological approaches to treat resistant hypertension has stimulated interest in invasive device-based treatments based on old concepts. In the absence of orally active antihypertensive agents, patients with severe and complicated hypertension were widely treated by surgical denervation of the kidneys until the 1960s, but this approach was associated with a high incidence of severe adverse events and a high mortality rate. A new catheter system using
\end{abstract}

Introduction:

Systemic hypertension is a major global public health concern. An estimated $30-40 \%$ of the adult population in the developed world suûer from this condition; Furthermore, its prevalence is expected to increase, especially in developing countries. ${ }^{1,2}$ Despite access to pharmacological therapies and resources to help patients achieve necessary lifestyle modifications, approximately half of patients fail to achieve recommended target blood pressure values. ${ }^{3}$ This can perhaps be attributed to inappropriate blood pressure

a. Dr. Mohammad Gaffar Amin, MD (Cardiology), Registrar, Department of Cardiology, Dhaka Medical College Hospital, Dhaka.

b. Dr. Hasna Fahmima Haque, FCPS (Medicine), SMO, Department of Internal Medicine, BIRDEM General Hospital, Shahbag, Dhaka.

Address of correspondence: Dr. Mohammad Gaffar Amin, MD (Cardiology), Registrar, Department of Cardiology, Dhaka Medical College Hospital, Dhaka, E-mail: gaffaramin@ gmail.com

Received: 04 June, 2012

Accepted: 21 June, 2012 radiofrequency energy has been developed, allowing an endovascular approach to renal denervation and providing patients, with resistant hypertension, with a new therapeutic option that is minimally invasive and can be performed rapidly under local anaesthesia. With this method the afferent and efferent sympathetic nervous fibers surrounding the renal artery are ablated precisely keeping the renal artery intact. To date, this technique has been evaluated only in open-label trials including small numbers of highly selected resistant hypertensive patients with suitable renal artery anatomy. The available evidence suggests a significant and persistent blood pressure-lowering effect and a very low incidence of short \& long term complications with no deleterious effects on renal function. These data, although promising, need confirmation in larger randomized controlled clinical trials with longerterm follow-up.

Key words: Renal denervation therapy, Resistant hypertension

(Birdem Med J 2012; 2(2): 104-112)

measurement, physician inertia, poor adherence to therapy due to polypharmacy, ineffective combinations or inadequate doses of antihypertensive drugs, excess salt intake, use of drugs known to induce or exacerbate hypertension, existence of secondary forms of hypertension and patient resistance to a lifelong regimen for a largely asymptomatic disease. ${ }^{4,5}$ However, even after adequately addressing the aforementioned contributing factors, blood pressure remains resistant to an appropriate multi-drug regime in a subset of hypertensive patients. ${ }^{6}$

Resistant arterial hypertension is defined as high blood pressure that cannot be adequately controlled according to the current guidelines (i.e., pressure of $>140 / 90 \mathrm{~mm}$ Hg in general; >130-139/80-85 mm Hg in patients with diabetes mellitus, $>130 / 80 \mathrm{~mm} \mathrm{Hg}$ in chronic renal disease) despite concurrent use of three or more antihypertensive drugs of different classes, including a diuretic, at their maximum or highest tolerated doses. ${ }^{7}$ Although the true prevalence of resistant hypertension is not known, Post hoc analyses of clinical trials have 
suggested a prevalence of $10 \%$ to almost 30\% among general hypertensive patients. ${ }^{8}$ According to the NHANES 2003-2008 survey, criteria for resistant hypertension are met by $8.9 \%$ of all US adults with hypertension and by $12.8 \%$ of the antihypertensive drug treated population. ${ }^{9}$ Patients with resistant arterial hypertension are at high risk of major cardiovascular events. ${ }^{7}$ Such patients are clearly appropriate for consideration of newer therapeutic approaches. Combining novel drug-, device-, and procedure-based strategies with improved utilization of existing therapies (including appropriate attention to diet, exercise, and weight control) may result in a major impact on the management of resistant hypertension. ${ }^{10}$ Novel approaches to the treatment of difficult-to-treat or resistant hypertension include: (i) drug-based strategies targeting traditional (e.g. the renin-angiotensinaldosterone system, RAAS) or less-well studied (e.g. endothelin or renalase) neurohumoral pathways; (ii) unique approaches involving gene and vaccine therapies; and (iii) device-based therapies (renal sympathetic nerve ablation or baroreceptor stimulation of the carotid sinus). ${ }^{10,11}$
Efforts to overcome resistance to pharmacotherapy have generated renewed interest into the role of the sympathetic nervous system as a therapeutic target for non-pharmacologic approaches because, a majority of patients with resistant hypertension and no identiûable secondary causes have activated sympathetic nervous system and increased sympathetic outûow. ${ }^{12}$ Surgical attempts to reduce sympathetic nerve activity and BP have been applied as early as the 1920s in severely hypertensive patients. ${ }^{13}$ Sympathetic nerve fibers innervate all organs that are involved in BP regulation such as the heart, the peripheral blood vessels and perhaps most importantly in the current context, the kidneys. The sophisticated network of efferent sympathetic and afferent sensory nerve fibers residing in the kidney, and their signaling pathways, provide the basis for the modulating influence of central integrative structures, in the brain stem, on renal effectors contributing to BP control. ${ }^{12}$ (Figure-1)

This review will focus on the role of renal sympathetic denervation therapy in the management of resistant hypertension.

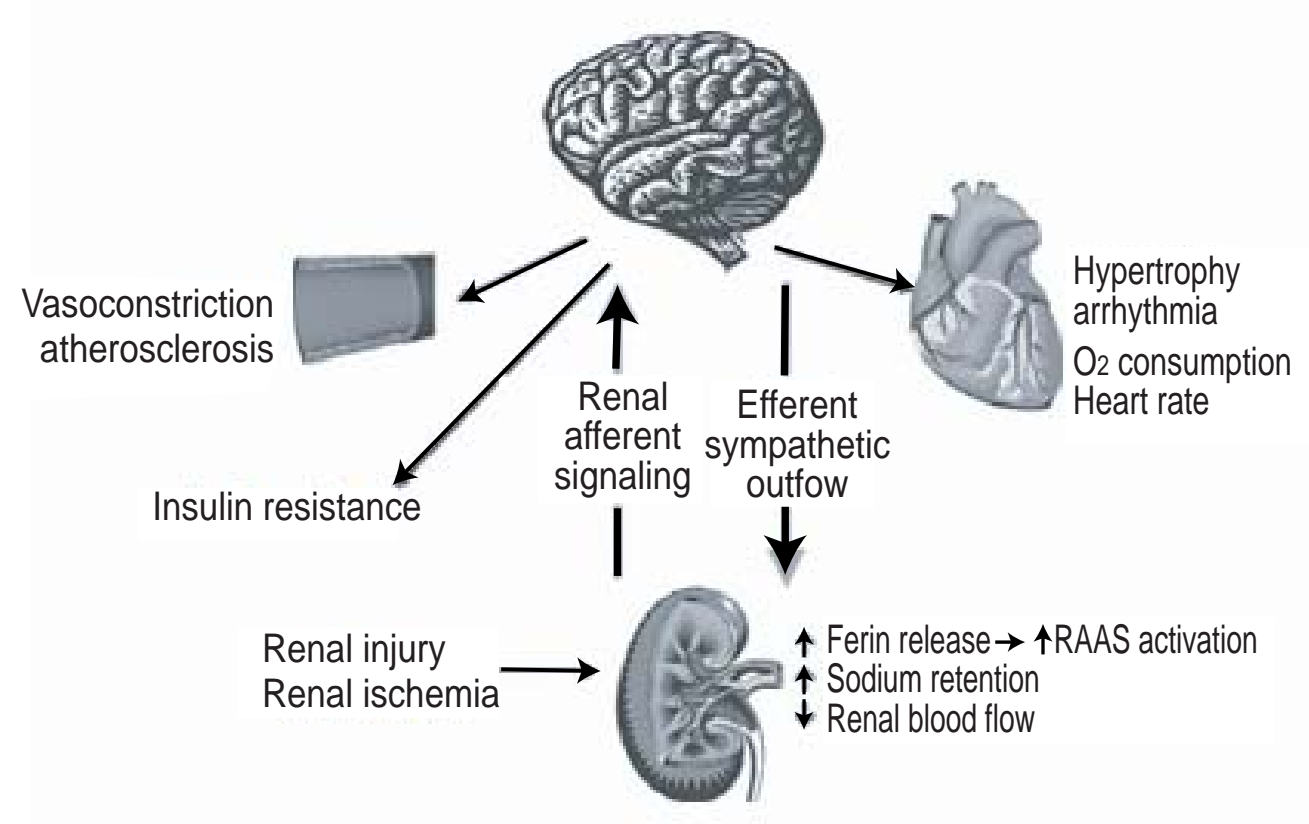

Fig.-1: The complex interaction between afferent sensory signaling from the kidney and efferent sympathetic outflow to the kidney. 


\section{The role of renal nerves in hypertension:}

Efferent Sympathetic Fibers: (Figure-2)

The central sympathetic efferent innervation of the kidney is achieved through a dense network of postganglionic neurons. The axons of preganglionic neurons exit the thoracic and lumbar sympathetic trunk $\left(\mathrm{T}_{10}-\mathrm{L}_{2}\right)$ and reach the pre-and para-vertebral sympathetic ganglia. Renal postganglionic nerves run alongside the renal artery and enter the hilus of the kidney. Thereafter, they divide into smaller nerve bundles, follow the blood vessels and penetrate the renal vasculature, the tubules and the juxtaglomerular apparatus. Renal sympathetic nerve activation enhances noradrenalin production from nerve endings and noradrenalin spillover, while interruption of renal sympathetic ûbers results in a marked decrease of noradrenalin spillover (up to 95\%). ${ }^{14}$ Renal efferent nerve activation exerts three signiûcant effects on renal function: increases rennin secretion rate through $\hat{a}_{1}$ adrenoceptors, enhances sodium and water reabsorption through $\mathrm{a}_{1 \mathrm{~B}}$ adrenoceptors, and induces renal vasoconstriction with renal blood ûow and glomerular ûow rate reductions through á ${ }_{1 \mathrm{~A}}$ adrenoceptors. ${ }^{15}$ These effects depend on the level of sympathetic overactivity, occur gradually, and are considered to play an important role in sodium-retaining conditions, such as congestive heart failure and hypertension. ${ }^{16}$

\section{Afferent renal sensory innervations: (Figure-2)}

Aûerent renal sensory nerves originate mostly from the renal pelvic walls; their cell bodies lie in the ipsilateral dorsal root ganglia $\left(\mathrm{T}_{6}-\mathrm{L}_{4}\right)$. From there, ascending signals travel to the renal cardiovascular centers in the CNS \& promotes vasopressin and oxytocin release from the neuro-hypophysis. ${ }^{14}$ Activation \& modulation of central sympathetic efferent outflow to the kidney can occur in response to increased afferent signaling from renal sensory fibers caused by various stimuli such as renal ischemia, hypoxia, and oxidative stress. ${ }^{17,18}$ This increased renal sensory afferent signaling directly

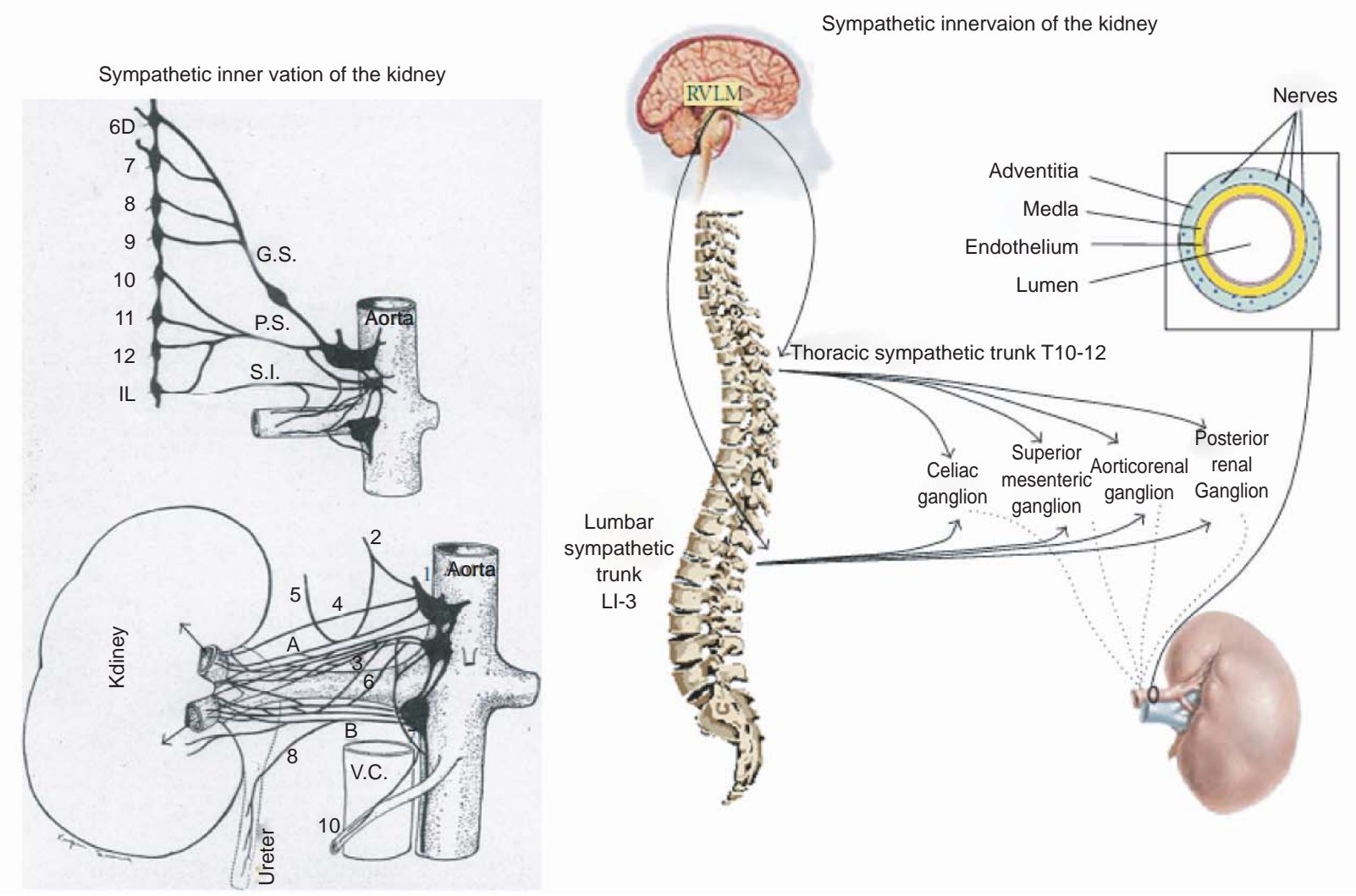

Fig.-2: Schematic representation of sympathetic innervations of the kidney. 
influences sympathetic outflow and is not only restricted to the kidneys but also affects other highly innervated organs such as the heart and peripheral blood vessels through its modulating effect on posterior hypothalamic activity. ${ }^{19}$ Overall renal afferent sensory ûbers may have important contribution in regulation of systemic vascular resistance and blood pressure control.

Sustained activation of renal efferent and/or afferent nerve activity is a common feature in patients with essential hypertension and undoubtedly contributes to their BP elevation; thus inhibition of renal sympathetic efferent or afferent nerves (or both) represents an attractive and logical target for the treatment of established hypertension as well as related disorders. ${ }^{10,12}$

\section{Renal sympathetic denervation:}

Historical Perspective:

Renal denervation in the management of hypertension has previously been explored in man via surgical nephrectomy, partial sympathectomy and even radical surgical sympathectomy (splanchnicectomy). ${ }^{20}$ The latter was very popular during the 1940s and 1950s for the treatment of malignant hypertension. ${ }^{21}$ Surgical renal denervation has been shown to be an effective means of reducing sympathetic outûow to the kidneys, augmenting natriuresis and diuresis, and reducing renin release, without adversely affecting other functions of the kidney such as glomerular ûltration rate (GFR) and renal blood flow (RBF). ${ }^{10}$ However, these early surgical approaches (e.g. splanchnicectomy) were complicated by severe orthostatic hypotension, orthostatic tachycardia, palpitations, breathlessness, anhydrosis, cold hands, loss of ejaculation, impotence, thoracic duct injuries, atelectasis and incontinence (both urinary and faecal). ${ }^{14,22}$ These debilitating side effects, along with the advent of anti hypertensive drug therapy, led these early surgical approaches to obscurity. The concept of renal sympathetic denervation as an effective management-tool of resistant HTN has lately been revived after the introduction of a new fascinating, catheter-based ablation-induced technique which allows selective \& direct denervation of the sympathetic nerves adjacent to the renal artery in an attempt to overcome the above mentioned, surgery-related problems. ${ }^{10,23}$

\section{Catheter-Based Renal Nerve Ablation:}

Percutaneous Catheter-based renal sympathetic nerve ablation is a rapid, minimally invasive technique. Owing to the unique anatomy of human renal nerves, their mesh-like organization around the renal artery, their close proximity to the vessel lumen arborizing throughout the adventitia, and the susceptibility of nerve tissue to radiofrequency (RF) energy, such an approach appeared feasible. ${ }^{12}$ The technique was pioneered by Sobotka, Krum, and others who performed the ûrst study of catheter-based RDT. ${ }^{24}$

The procedure requires invasive access to the renal artery, which is usually obtained percutaneously through the femoral artery. Before introducing the specifically designed treatment (ablation) catheter (Symplicity ${ }^{\mathrm{TM}}$ Catheter System, Ardian/Medtronic Inc., California, USA) into the renal artery, anatomic eligibility is confrmed by renal angiography to exclude severe renal artery stenosis or other abnormalities. Following this, a guide-catheter is engaged in the osteum of one renal artery and the treatment (ablation) catheter is advanced through the renal artery under fluoroscopic guidance with the tip of the catheter placed at the distal section of the renal artery. Then the endothelial layer of the renal artery is focally heated to 50 to 70 degrees Celsius by delivering discrete lowpower (<8watts) radiofrequency (RF) energy for 02 minutes through an electrode, placed at the tip of the treatment catheter. The catheter is then withdrawn from distal to proximal in steps of at least $5 \mathrm{~mm}$, with ablation at each new site; this results in four to six areas of ablation distributed longitudinally and circumferentially along the renal artery (Figure-3). The purpose of radiofrequency energy delivery is to cause transmural lesions and damage the sympathetic ûbers traveling in the adventitia of the renal arterial wall. The same process is then repeated at the contralateral renal artery. This localized procedure lasts about 40 minutes, has no systemic side-eûects and the procedural and recovery times are very short. ${ }^{12,23,25}$

Another type of catheter for chemical sympathectomy, achieved by local guanethidine infusion through a microneedle, is currently under investigation. ${ }^{23}$ 


\section{Box-1: Criteria to be met for interventional renal denervation ${ }^{24,26}$}

- $\quad$ Office systolic blood pressure > $160 \mathrm{mmHg}$ ( $>150 \mathrm{mmHg}$ for patients with diabetes mellitus type 2 .

- Intake of $>3$ antihypertensive substances (true resistance in patient with good compliance)

- Exclusion of secondary causes of hypertension

- Normal or only slightly reduced renal function (estimated glomerular filtration rate $>45 \mathrm{~mL} / \mathrm{min} / 1.73 \mathrm{~m}^{2}$ )

- Suitable renal artery anatomy: no previous renal artery interventions, no significant stenosis or other abnormalities of the renal arteries.

All of these criteria should be fulfilled.
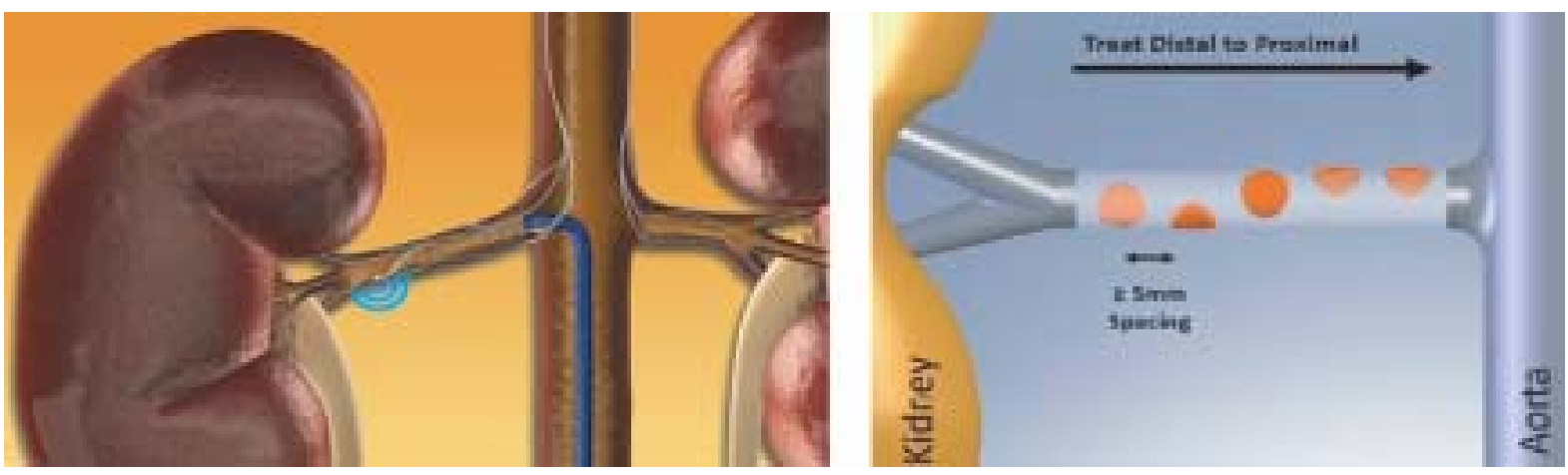

\section{Clinical studies in humans:}

Interventional renal denervation for treatment of resistant arterial hypertension was successfully employed and clinically evaluated in the multicenter safety and proofof-principal study Symplicity HTN-1 ${ }^{24}$ and the randomized controlled trial Symplicity HTN-2. ${ }^{26}$

The initial cohort study Symplicity HTN-1, performed by Krum et al, was designed as an observational firstin-man evaluation of the safety and BP-lowering efficacy of selective renal nerve ablation. A total of 45 consecutive patients (mean age of $58 \pm 9$ years), with treatmentresistant hypertension (baseline BP of 177/101 \pm 20/15 $\mathrm{mm} \mathrm{Hg}$ ), taking on an average $4.7 \pm 1.5$ antihypertensive drugs were selected for the study, and all of them were followed-up for 12 months post-procedure. The procedure was associated with a significant reduction in both office SBP and DBP by 14/10, 21/10, 22/11, 24/ 11, and 27/17 mm Hg at one, three, six, nine, and 12 months, respectively (Figure-4); this was also paralleled by signiûcant reductions in ambulatory blood pressure monitoring (ABPM) readings. The reduction in sympathetic activity due to the renal artery denervation was confirmed by a significant decrease of $47 \%$ (95\% CI 28-65\%) in the renal norepinephrine spillover rate.
Furthermore, muscle sympathetic nerve activity (MSNA) studies suggested a reduction in afferent sympathetic activity, i.e. reduced central sympathetic drive. ${ }^{24}$

A key issue with this RF energy denervation approach was whether anatomical and/or functional re-growth of renal sympathetic nerves occurs, abrogating the BPlowering beneûts observed for 12 months in the Symplicity HTN-1 study. Such re-growth has been observed in other conditions where sympathetic nerves have been disrupted, such as in organ transplantation. ${ }^{27}$ In this regard, an extended follow-up study (24 months) ${ }^{28}$ was carried out, on an expanded group of patients ( $\mathrm{n}=153$, including the patients of Symplicity HTN-1 trial) with resistant hypertension who underwent renal denervation, to see the longer-term durability of the BP-lowering effect of this procedure; the results of the study further supported the efficacy of renal nerve ablation with post-procedure office BP being reduced by 20/11, 24/10, 24/12, 25/12, 29/17, and 33/14 mm Hg at $1,3,6,12,18$, and 24 months, respectively. Based on these data durability of the effect of renal denervation therapy appears to be evident up to at least 2 years.

Following the first-in-man proof-of-concept and safety study, a randomized controlled clinical trial Symplicity 
HTN-2 ${ }^{26}$ was carried out by Esler et al. which enrolled a total of 106 patients, between June 2009 and January 2010, from 24 centers in Australia and Europe. Inclusion criteria were similar to those of the Symplicity HTN-1 study and the enrolled 106 drug-resistant hypertensive patients were then randomized in a 1:1 ratio to undergo renal denervation while continuing prior medical-therapy (treatment group; $n=52$ ) or to continue prior medical therapy alone (control group; $n=54$ ). The seated office $\mathrm{BP}$, at 6 months follow up, in the renal denervation group was reduced by 32/12 mm Hg (SD 23/11) from 178/96 mm $\mathrm{Hg}$ at baseline ( $<<0 \cdot 0001$ for systolic and diastolic BP). By contrast, oûce BP did not diûer from baseline in the control group [change of $1 / 0 \mathrm{~mm} \mathrm{Hg}$ (SD 21/10); baseline of $178 / 97 \mathrm{~mm} \mathrm{Hg}, \mathrm{p}=0.77$ for systolic BP and $\mathrm{p}=0.83$ for diastolic BP]. (ûgure-5) Therefore, a 33/11 mm Hg reduction in blood pressure was noted in the renal denervation group compared with the control group $(\mathrm{p}<0.0001$ for systolic and diastolic BP) during 6-month follow-up. These changes were paralleled by similar reductions in home-based BP measurements \& 24-h ambulatory BP recordings in the treatment group and the need for further anti-hypertensive drugs was also substantially reduced in that group.

These available evidences indicate that catheter-based renal denervation results in a substantial and sustained $\mathrm{BP}$ reduction in patients with drug-resistant hypertension.

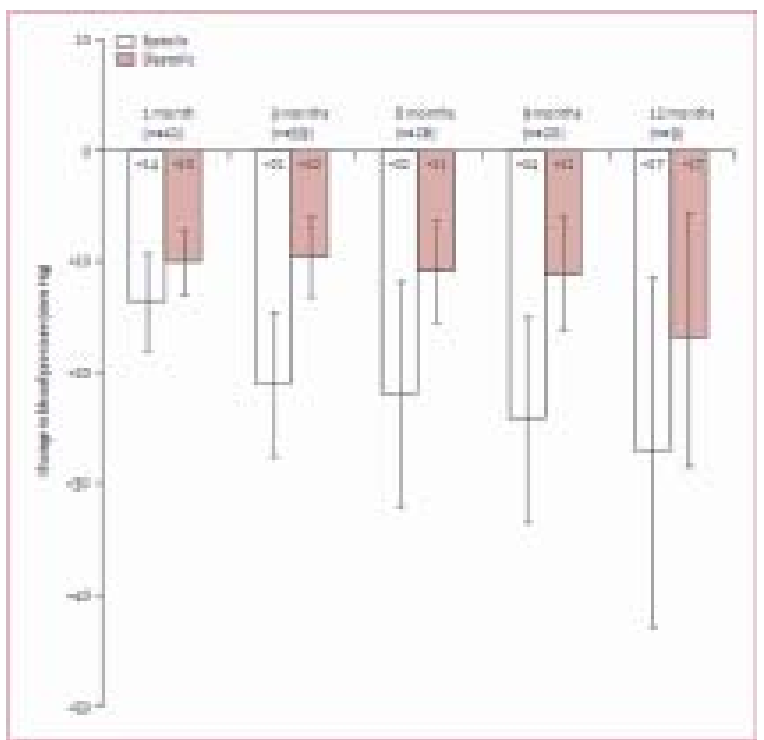

Fig.-4: Change in oûce BP (95\% CI) at 1, 3, 6, 9, and 12 months (Symplicity HTN-1 study) ${ }^{24}$ (Numbers in parentheses indicate patients who had attended each predeûned visit)

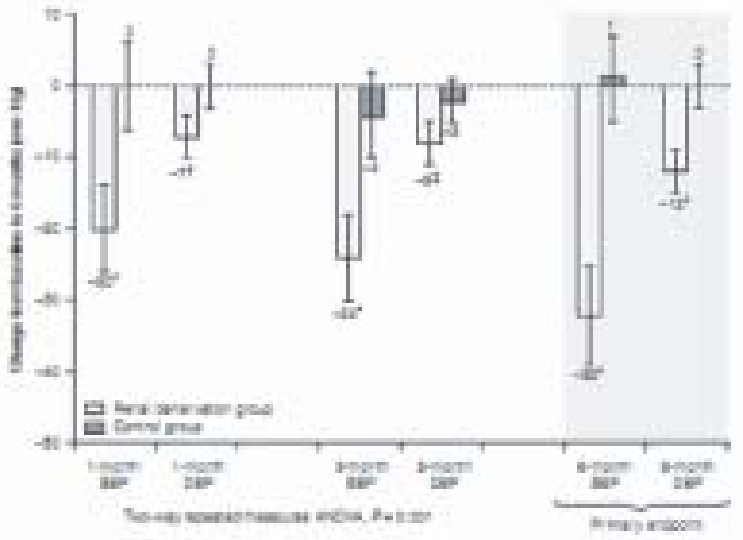

Fig.-5: Changes in systolic and diastolic $\mathrm{BP}$ ( $\mathrm{mm} \mathrm{Hg} \pm$ $S D)$ from baseline in renal denervation group and control group at 1, 3, and 6 months follow-up (Symplicity HTN-2 trial) ${ }^{26}{ }^{*} P<0.0001,+P=0.002$, $\ddagger P=0.005$.]

\section{Mechanisms of blood pressure reduction by RDT:}

Renal sympathetic afferent and efferent ûbres are comingled in an arcade about the renal artery; so renal sympathetic ablation usually results in simultaneous reduction of both the pathways. As, mentioned earlier, sustained overactivity of renal efferent and/or afferent nerves is a common feature in patients with longstanding resistant hypertension, ablation of both the pathways contributes significantly in BP reduction. Ablation of renal efferent fibres attenuates local (renal) sympathetic activity which can be detected by significant reduction of post-ablation renal norepinephrine spillover rate. Ablation of renal afferent fibres attenuates both local (renal) \& systemic sympathetic activity by substantial and progressive reduction in central sympathetic outfow via central integration of altered signaling from the denervated kidney. The attenuation of whole body (systemic) sympathetic activity after renal denervation can be veriûed by significant reduction of both post-ablation whole-body norepinephrine spillover rate and muscle sympathetic nerve activity (MSNA). In addition to these direct effects, a substantial reduction in renal renin secretion has also been observed after renal denervation which might contribute to the BP-lowering effect of this procedure; but this needs to be evaluated further. ${ }^{10,12,14,23}$

The long-term persistence of blood pressure reduction following renal denervation generates several 
hypotheses: re-innervation of the denervated renal sympathetic fibres either does not occur within the 2year time frame or if it does occur, it remains nonfunctional; denervation-induced vascular remodeling decreases systemic vascular resistance and maintains blood pressure reduction; hemodynamic changes induced by renal denervation mediate longterm blood pressure reduction; central baro-reûex resets to lower blood pressure values; inûuence of CNS on peripheral resistance is blunted \& vasodilating mechanisms are enhanced; vasoconstrictive counterregulatory mechanisms are suppressed or attenuated; All these mechanisms probably contribute to the sustained blood pressure reduction. Much research is still required to clarify the mechanisms of induction and maintenance of blood pressure reduction by renal denervation. $^{23}$

\section{Short and long-term safety:}

Catheter-based renal denervation seems to be well tolerated. Results reported so far indicate that adverse effects are rare and not serious. ${ }^{23}$ In the extended followup study of 153 patients ${ }^{28}$ who underwent renal denervation, acute complications were reported only in four patients (3\%). Pseudoaneurysm developed at the femoral access site in three patients during catheterization, whereas renal artery dissection was observed in one patient before radiofrequency ablation and was managed by renal artery stenting, with no longterm complications for any of these four patients. One patient required stenting of a renal artery ostial stenosis that was present at baseline but grew by 6 months, although no RF energy was delivered at that location. In the Symplicity HTN-2 trial ${ }^{26}$ peri-procedural events consisted of one femoral artery pseudoaneurysm, one post-procedural drop in BP, one urinary tract infection, one extended hospital admission for assessment of paraesthesias, one case of back pain and seven cases of transient intra-procedural bradycardia; all these events were treated effectively with no further sequelae. A major concern with renal denervation is whether postprocedural renal artery stenosis develops due to endovascular RF-induced intimal injury. ${ }^{14,23,29}$ Although tissue damage and ûbrosis have been observed with radiofrequency ablation in other areas of the body (i.e., left atrium for atrial ûbrillation ${ }^{30}$, tumor ablation etc.), no signs of renal artery stenosis, at the site of RF delivery, have been observed during the six- month follow-up period in the Symplicity HTN-2 study ${ }^{26}$, using renal duplex imaging \& magnetic resonance angiography (MRA), and no such evidence has also been found in the expanded group of patients with 02 years follow-up ${ }^{28}$. This is probably because, the energy delivered in other conditions is much higher compared to the one required for RDT, thus rendering RDT potentially harmless. ${ }^{14,29}$

No statistically signiûcant changes on renal function, assessed by serum creatinine, estimated glomerular ûltration rate (eGFR), cystatin-C and urinary albumincreatinine ratio, were observed with renal denervation during the follow-up periods in clinical trials. ${ }^{24,26,28}$ Standard measures of renal function deterioration (doubling of serum creatinine, stage 4 chronic kidney disease, or progression to dialysis) were not met by any patient. 23

All these available evidences indicate that catheterbased renal denervation has a favorable short \& longterm safety profile.

\section{Future perspectives:}

Given the overwhelming evidence of a crucial role of activation of the sympathetic nervous system, in particular the renal sympathetic nerves, in hypertension, cardiovascular, and metabolic disease states, it is tempting to speculate about a potential therapeutic role of renal denervation in these conditions. ${ }^{12}$ Extensive research is needed to investigate whether RSD can be applied in less severe forms of hypertension with an aim to reduce or even abandon pharmacotherapy, for hypertensive patients with drug-noncompliance, for hypertensive patients intolerant to medication, and in several other disease conditions associated with central sympathetic overactivity; ${ }^{12,14}$ proposed potential therapeutic benefits of RDT in such disease conditions are as follows: ${ }^{10,23}$

(a) Improvement in blood pressure control and cardiovascular outcomes in congestive heart failure;

(b) Regression of left ventricular hypertrophy;

(c) Better rate control or prevention of atrial ûbrillation;

(d) Control of sympathetic-mediated lethal arrhythmias;

(e) Better control of angina pectoris;

(f) Attenuation of renal function deterioration in chronic kidney disease; 
(g) Reduction of urinary albumin excretion in diabetic nephropathy;

(h) Improvements in insulin resistance;

(i) Reduced cardiovascular events in end-stage renal disease;

(j) Better blood pressure control in mild and end-stage renal disease;

(k) Better blood pressure control in obesity-related hypertension; and

(l) Better blood pressure control in obstructive sleep apnea.

Thorough testing of renal denervation in the clinical settings outlined above in adequately designed controlled trials is now required to determine the safety and full potential of this approach.

\section{Conclusion:}

Resistant hypertension represents a signiûcant challenge in everyday clinical practice. Catheter-based RDT represents an innovative, new, safe \& welltolerated therapeutic technique to eûectively reduce blood pressure in these patients. Further extensive research, in the form of larger randomized controlled clinical trials with more prolonged and in-depth followup, is required to reveal the underlying mechanisms of denervation-induced blood pressure reduction, to evaluate the relative contributions of efferent and/or afferent denervation on blood pressure reduction, to explore the effects of renal denervation on counterregulatory mechanisms participating in blood pressure homeostasis \& to assess the impact of renal denervation on cardiovascular mortality \& morbidity.

RDT will signiûcantly enrich the therapeutic armamentarium for hypertension treatment and control in future. Indeed if RDT proves to have long-lasting beneûcial eûects, patients would have a choice between interventional therapy for cure of hypertension and lifelong drug therapy with associated expense and potential side eûects. It may be far-fetched, but, RDT may become in the future a viable alternative to lifelong drug therapy.

\section{References:}

1. Lloyd-Jones D, Adams R, Carnethon M, et al. Heart disease and stroke statistics - 2009 update: a report from the American heart association statistics committee and stroke statistics subcommittee. Circulation 2009; 119: 480-86.
2. Kearney PM, Whelton M, Reynolds K, Muntner P, et al. Global burden of hypertension: analysis of worldwide data. Lancet 2005; 365: 217-23.

3. Lloyd-Jones D, Adams RJ, Brown TM, et al. Executive summary: heart disease and stroke statistics: 2010 update. A report from the American Heart Association. Circulation, 2010; 121: 948-54.

4. Saraûdis PA, Bakris GL. Resistant hypertension: an overview of evaluation and treatment. J Am Coll Cardiol 2008; 52: 1749-57.

5. Faselis C, Doumas M, Papademetriou V. Common secondary causes of resistant hypertension and rationale for treatment. Int J Hypertens 2011; 2011: 236-39.

6. Calhoun DA, Jones D, Textor S, et al. Resistant hypertension: diagnosis, evaluation and treatment. Hypertension 2008; 117: 510-26.

7. Calhoun DA, Jones D, Textor S, et al. Resistant hypertension: diagnosis, evaluation, and treatment: a scientific statement from the American Heart Association Professional Education Committee of the Council for High Blood Pressure Research. Circulation 2008; 117: e510-26.

8. Fagard RH. Resistant hypertension. Heart 2012; 98: 25461.

9. Persell SD. Prevalence of resistant hypertension in the United States, 2003-2008. Hypertension 2011; 57: 107680 .

10. Krum H, Schlaich M, Sobotka P, et al. Novel procedureand device-based strategies in the management of systemic hypertension. Eur Heart J 2011; 32: 537-44.

11. Paulis L, Unger T. Novel therapeutic targets for hypertension. Nat Rev Cardiol 2010; 7: 431-41.

12. Schlaich MP, Krum H, Sobotka PA, et al. Renal denervation and hypertension. Am J Hypertens 2011; 24: 635-42.

13. Smithwick RH, Thompson JE. Splanchnicectomy for essential hypertension; results in 1,266 cases. J Am Med Assoc 1953; 152: 1501-4.

14. Papademetriou V, Doumas M, Tsiouûs K. Renal sympathetic denervation for the treatment of difûcultto-control or resistant hypertension. Int J Hypertens 2011; 2011: 196518.

15. DiBona GF, Esler M. Translational medicine: the antihypertensive effect of renal denervation. Am J Physiol Regul Integr Comp Physiol 2010; 298: R245-R253.

16. Campese VM, Ku E, Park J. Sympathetic renal innervations and resistant hypertension. Int J Hypertens 2011; 2011: 814354.

17. Ye S, Zhong H, Yanamadala V, et al. Renal injury caused by intrarenal injection of phenol increases afferent and efferent renal sympathetic nerve activity. Am J Hypertens 2002; 15: 717-24. 
18. Campese VM. Neurogenic factors and hypertension in renal disease. Kidney Int Suppl 2000; 75: S2-S6.

19. Campese VM, Kogosov E, Koss M. Renal afferent denervation prevents the progression of renal disease in the renal ablation model of chronic renal failure in the rat. Am J Kidney Dis 1995; 26: 861-65.

20. Morrissey DM, Brookes VS, Cooke WT. Sympathectomy in the treatment of hypertension; review of 122cases. Lancet 1953; 1: 403-8.

21. Doumas M, Faselis C, Papademetriou V. Renal sympathetic denervation and systemic hypertension. Am J Cardiol 2010; 105: 570-76.

22. Allen TR. Current status of lumbar sympathectomy. Am Surg 1976; 42: 89-91.

23. Doumas M, Faselis C, Papademetriou V. Renal sympathetic denervation in hypertension. Curr Opin Nephrol Hypertens 2011; 20: 647-53.

24. Krum H, Schlaich M, Whitbourn R, et al. Catheter-based renal sympathetic denervation for resistant hypertension: a multicentre safety and proof-of-principle cohort study. Lancet 2009; 373: 1275-81.
25. Mahfoud F, Himmel F, Ukena C, et al. Treatment Strategies for Resistant Arterial Hypertension. Dtsch Arztebl Int 2011; 108(43): 725-31.

26. Esler MD, Krum H, Sobotka PA, et al. Renal sympathetic denervation in patients with treatment- resistant hypertension (the Symplicity HTN-2 Trial): a randomized controlled trial. Lancet 2010; 376: 1903-9.

27. Wilson RF, Christensen BV, Olivari MT, et al. Evidence for structural sympathetic reinnervation after orthotopic cardiac transplantation in humans. Circulation 1991; 83 : 1210-20.

28. Symplicity HTN-1 Investigators. Catheter-based renal sympathetic denervation for resistant hypertension: durability of blood pressure reduction out to 24 months. Hypertension 2011; 57: 911-17.

29. Gewirtz JR, Bisognano JD. Catheter-based renal sympathetic denervation: A targeted approach to resistant hypertension. Cardiol J 2011; 18(1): 97-102.

30. Cappato R, Calkins H, Chen SA, et al. Prevalence and causes of fatal outcomes in catheter ablation of atrial fibrillation. J Am Coll Cardiol 2009; 53: 1798-1803. 